questions. Perhaps it would be desirable for the examiner on botany to announce the works on the subject, within the limits of which he would restrict himself in writing the questions.

If the present system should continue I fear that the University of London will be closed to all but those who have carried away prizes on several subjects from the schools. I do not desire that the examinations should be less rigid, and the degrees of the university less easy of attainment, but that men who really have studied up for the examination, as a whole, should not be rejected for not having got up that which they did not conceive to come within the requirement of the regulations of the university. "Fair play is a jewel." I am, Sir, your's obediently,

A nother Medical Student. London, Sept. 14, 1843.

\section{REMOVAL OF CONSTIPATION.}

\section{To the Editor of THE LANCET.}

SIR, $\rightarrow$ A case of obstinate constipation has lately been treated by me most successfully with Read's newly-invented flexible tube, which the maker has added to his enema-syringe. A lady, aged eighty-one years, has for several years been subject to a sluggish state of the bowels, frequently requiring powerful aperients, together with enemata, to make any impression upon them. The bowels had not been moved for twelve days, the usual remedies (castor oil, \&c., and enemata) had been tried, but without effect, and the patient sank into a state of collapse and insensibility. The colon was distended to an immense extent. I thought that hardened fæces might be the cause; I therefore, as a last resource, tried the tube in question, sixteen inches of which I passed into the colon, with the view of pushing it through the fæces and letting out the confined air. The tube slipped into the distended intestine, through the fæces, and immediately after I injected a small quantity of water, to clear the orifices of the tube. On removing the syringe from the tube an abundance of air escaped, followed by at least three quarts of liquid frees. I then injected more water into the intestines, and so completely removed the olistruction, the old lady becoming sensible, and perfectly free from pain, and after three hours comfortable sleep she was restored. I have since, twice, used the same means with regard to this patient, and in each instance with equal success, aud she is at this time in excellent health. I feel confident that had I not used this great length of tube the patient would not have survived. I am, Sir, your obedient servant,

Charles Newington, Surgeon,

Ticehurst, near Lamberhurst, Sept, 18, 1843.

\section{HOSPICE DES INCURABLES, PARIS.}

VIOLENT AND FATAL CASE OF TURUSH IN AN OLD MAN.

ON the 10th of February, in the present year, a man, atat. 75, who had been successfully treated for pneumonia, and was on the point of being discharged, was attacked suddenly with diarthœa, which no ordinary means were able to suppress. At the same time an erythematous eruption extended down the posterior part of the thighs. The pulse rose in a few hours from 80 to 120 .

11. The diarrhoea continued; pulse weak and 130 , though regular. The face assumed a dull-yellow colour, which was retained to the last. Similar symptoms continued to the 16th, when the papillæ of the tip of the tongue were swollen, and the whole organ was soon of a deep red, as was, in two more days, all the interior of the mouth. On the 20th the buccal surface and tongue began to assume, in spots, a dirty whiteness, which by the 24th had spread all over the palate, uvula, tonsils, and pharynx, which were also covered with a thick and unpleasant secretion. Diarrhoea persisted.

26. The mouth was so inflamed and pain. ful that the patient could not bear even to gargle it. Acute pain in the epigastric region; mucous vomitings, and no aliment entered the stomach that was not immediately rejected. Abdomen meteorised; stools continual, consisting of muculent malters, blood, and false membranes. On the 3rd of April the period of prostration commenced; the pulse fell to 100 , and the extremities were cold. The bloody stools and vomiting continued, and the patient died on the 9 th.

On opening the body the mucous mem. brane of the mouth and pharyns was found inflamed, and the papillse of the tongue salient, and apparently deprived of epidermis. False membranes adhered to the base of the tongue and left tonsil, which were readily scraped off with the scalpel. The mucous membrane of the cesophagus was \$o softened by inflammation as to break down under the least force; and in many places in its lower quarter it was covered with circular zones, irregular patches, and spots of muquet. Several ulcerations also existed. No false membranes were discoverable in the stomach, but that organ was the seat of much vascular injection. The small intestinn had apparently escaped all morbid action, but the large intestine, particularly the descending colon, presented the traces of old inflammation, with false membranes, re. sembling entirely those in the oesophagus; some ulcerations were also present here. The rectum and colon were thickened; most of the other organs were healthy, - Gazette des Hôpitaux. 